\title{
Integration of Environmental and Sustainability Management Practices into Construction Industry: A Case Study
}

\author{
Gary Peach \\ gary.peach@mottmac.com \\ Mott MacDonald, Doha, Qatar \\ Dila Ersenkal \\ dila.ersenkal@mottmac.com \\ Mott MacDonald, Doha, Qatar \\ George Daoutis \\ george.daoutis@mottmac.com \\ Mott MacDonald, Doha, Qatar \\ Sotirios Koropoulis \\ s.koropoulis@auccqatar.com \\ HBK-PORR JV, Doha, Qatar \\ Pavel Zuzula \\ pavel.zuzula@auccqatar.com \\ HBK-PORR JV, Doha, Qatar \\ Biliana Karamukova \\ b.karamukova@auccqatar.com \\ HBK-PORR JV, Doha, Qatar
}

\begin{abstract}
Integration of environmental and sustainability management into the construction industry has become essential as a result of a need to improve financial performance, adopt international protocols in a global marketplace, address stakeholder interests, and attain high environmental performance. Communities also expect organizations to comply with environmental standards and reduce the environmental impacts in their daily operations. That may be a challenge, but it is also an opportunity for the organizations to demonstrate their commitment to environmental responsibility and sustainability. Environmental impacts arising from the construction industry and the consequences could be challenging if appropriate practices are not in place. Therefore, adopting responsible approach to management of environmental matters and embedding the environmental and sustainability principles into the full lifecycle of the projects, starting as early as conceptual design, is crucial for long-term success. Responsible environmental management and commitment to sustainability has been central to Public Works Authority (PWA)'s success as a leading government organization. This is evident from the manner in which PWA is requesting all contractors and consultants working on behalf of PWA projects to develop and implement Environmental Management System (EMS) and comply with international sustainability rating schemes for their projects. This paper provides information on a case study; namely the Musaimeer Pumping Station and Outfall (MPSO) project and discusses the strategies, systems, procedures, and tools
\end{abstract}


developed and implemented by the Project Management Consultant (PMC) and the Contractor to achieve and exceed PWA's environmental and sustainability requirements for the project.

Keywords: Construction innovation; Manufacturing innovation; Road construction; Case study; Project management; Plastic bags; Glass bottle

\section{INTRODUCTION}

Musaimeer Pumping Station and Outfall (MPSO) project area is located nearshore to the southwestern area of Doha, in-between the RAF Desalination Plant and Hamad International Airport. This particular area has experienced rapid expansion of growth in recent years, with ongoing developments. Therefore, the need to increase drainage capacity in order to accommodate additional storm water runoff and constructional activities has become critical. PWA has developed and implemented multiple projects, including the MPSO Project.

The MPSO project comprises a pumping station to handle a peak flow rate of 19.7 $\mathrm{m}^{3} / \mathrm{s}$; a $10 \mathrm{~km}$ long $3.7 \mathrm{~m}$ diameter marine tunnel outfall, an offshore riser shaft and 84 port diffuser field. HBK-PORR JV is the Design, Build, Operation and Maintain Contractor for the construction of the MPSO Project, and Mott MacDonald Ltd. is the Project Management Consultant (PMC) Company.

Construction activities of the MPSO project comprise a wide range of activities including but not limited to excavation and dewatering, tunneling, marine and offshore works including dredging, and drilling. These activities have the potential to affect a broad spectrum of environmental aspects. Environmental concerns associated with the MPSO project include, but are not limited to:

- Releases of airborne particulate matter and air emissions.

- Impacts on aquatic ecosystems.

- Impacts on terrestrial ecosystems.

- Impacts on local and regional surface water and groundwater flow.

- Wastewater from site runoff.

- Waste generation.

- Noise.

- Planned and accidental releases of pollutants.

- Social impacts.

The objective of this paper is to provide an overview of the environmental and sustainability practices implemented at the MPSO project site in order to facilitate and encourage continual improvement in the environmental performance of the project throughout the project life cycle.

\section{ENVIRONMENTAL REQUIREMENTS FOR THE PROJECT}

Responsible environmental management and commitment to sustainability has been central to PWA's success as a leading government organization. This is evident from the manner in which PWA is requesting all contractors and consultants working on behalf of PWA projects to develop and implement an Environmental Management System (EMS) and comply with international sustainability rating schemes for their projects. PWA is 
defining project requirements, setting public tenders for the execution of works, and defining the requirements for environmental management and sustainability.

It is also a requirement of Qatar Construction Specifications (QCS, 2014) that all companies engaged to undertake work on behalf of the PWA and PWA, have an existing or working towards the development and implementation of an Environment, Health and Safety Management System (EHSMS). Sections below provide information on the contractual requirements set forth for the Consultant and the Contractor by PWA for the MPSO project.

\subsection{Requirements for PMC}

PWA has set forth environmental management requirements for the MPSO project in the Professional Services Agreement (PSA) (PWA, 2017) signed with the Project Management Consultant (PMC) - Mott MacDonald. The contract is comprehensive and provides detailed information on the necessary actions to be implemented by the PMC to ensure that the environmental impacts associated with the MPSO project are managed effectively. These include but are not limited to the following:

- Appointment of a Senior Civil/Environmental Engineer.

- Requirements for Core Team Design and Construction Supervision Team to have experience in environmental protection aspects of the construction and operation of similar large diameter tunneling projects and deep below ground pumping stations/ structures; demonstrated knowledge of environmental regulations; demonstrable experience of environmental management and permitting; and knowledge of Qatar environmental legislation.

- Undertaking an environmental assessment during the planning and implement of the project.

- Instigation of an Environmental Management System.

- Development of an Environmental Management Plan and associated procedures.

- Compliance with environmental obligations.

- Adherence to the requirements of applicable environmental specifications, codes and other requirements.

- Monitoring the Contractor's compliance with environmental management requirements.

- Coordination of environmental activities including but not limited to environmental permit applications, review of Contractor's environmental submissions, and undertaking environmental surveys.

- Ensuring submission of necessary documentation for environmental permits.

- Conducting EMS audits to verify the implementation and maintenance of Contractor's EMS.

- Submission of monthly progress reports that include a section on environmental management.

- Identifying and keeping a record of project lessons learned, including environmental issues.

\subsection{Requirements for the Contractor}

Similar to the PSA made with the PMC, environmental management requirements 
for the Contractor has been extremely well defined in PWA's contract made with the Contractor HBK-PORR JV (PWA, 2017). There is a detailed chapter on 'Environmental Management' to furnish the Contractor with the Authority's fundamental requirements for environmental management to be delivered by the Contractor throughout all stages of the project. A summary of these requirements includes, but is not limited to the following:

- Mobilization of a dedicated Environmental Manager, with a minimum of 5 years' experience in an environmental manager role, located permanently in Doha for the duration of the project and with the authority to enable the discharge of all environmental requirements.

- Proactively demonstrating implementation of a close working interface between the engineering and environmental technical and management disciplines.

- Designing, implementing and effectively resourcing a comprehensive Environmental Management System (EMS), compliant with Authority, Government, International standards and recognized best practice, that will include a range of management plans specific to Engineering / Environmental design integration, environmental impact / risk assessment, construction environmental management planning, site supervision, project environmental / sustainability performance and auditing.

- Establishing an ISO 14001 compliant (or an equivalent, internationally recognized system EMS) to be audited at least twice a year to ensure ongoing compliance.

- Obtaining all necessary permits for the MPSO project, and preparing all reports required by the permits.

- Compliance with the requirements of the Authority, national legislation of the State of Qatar, the international legislation / conventions ratified by the State of Qatar, and industry recognized best practice.

- Compliance with all requirements of the Ministry of Municipality and Environment and in particular the requirements of the project environmental permit obtained for the MPSO Project.

- Adherence to the requirements of applicable environmental specifications, codes and other requirements.

- Application of international standards where (i) Qatar National Standards have not been developed for a particular parameter, or (ii) there is agreement with the Engineer that use of an international standard provides greater environmental security, without compromising compliance with Qatar National Standards.

- Submission of construction environmental management plan and safety management plan.

- Ensuring that all mitigation measures necessary, including those identified in the Environmental Impact Assessment are implemented during the project.

- Conducting all necessary environmental surveys and collect environmental data; i.e. detailed topographic survey, detailed bathymetric surveys of the diffuser area, condition survey of access roads to the site, marine geotechnical investigations, etc.

- Establishing an environmental monitoring programme that includes on site air quality monitoring, monitoring ground water levels on the site, noise monitoring, seawater quality sampling and analysis programme, continual online seawater quality monitoring via buoys. 
- Developing a protocol, designing and implementing systems for sharing seawater quality analysis and online monitoring data, with third parties in consultation with MME, Kahramaa and Ras Abu Fontas Power and Water Desalination Plant.

- Implementing risk management to cover all project risks not restricted only to health and safety matters; but also risks to the environment, the design, the program for design, the cost of design, the construction of the tunnel and shafts and the associated works, the program for construction and cost of construction.

- Developing a detailed Environmental Risk Assessment (ERA) Programme all environmental aspects and impacts of all works.

- Conducting hazard and operability (HAZOP) and control hazard and operability (CHAZOP) studies.

- Identifying and registering the project with CEEQUAL International (CEEQUAL, 2015) and achieve a score of 'GOOD' under 'CEEQUAL International' scheme.

- Provision of monthly environmental progress reports that include environmental issues.

- Conducting bi-weekly site inspections and semi-annual audits.

- Delivering environmental management performance to international standards.

\section{ENVIRONMENTAL PRACTICES AT MPSO PROJECT SITE}

Comprehensive definition of the environmental management requirements in the contract has significantly contributed to the high environmental performance of the MPSO project. Moreover, the appointment of consultants and contractors that have international best practice experience in environment and sustainability field, with mature management systems in place, has definitely been important contributor for the continual improvement of the environmental and sustainability performance of the project and raising the bar in the construction industry. Table 1 presents a summary of the selected environmental practices being implemented at the MPSO project site.

Table 1: Summary of Environmental Practices at MPSO Project Site

\begin{tabular}{|l|l|}
\hline Subject & Practices at MPSO Site \\
\hline Leadership & $\begin{array}{l}\text { Both the PMC and the Contractor demonstrate leadership and commitment for the } \\
\text { implementation of an effective environmental management system for the MPSO } \\
\text { project and enhancing the project's environmental performance. }\end{array}$ \\
\hline Environmental Policy & $\begin{array}{l}\text { A project environmental policy has been developed and is being implemented. The } \\
\text { policy is displayed at various locations at the site and communicated to all staff and } \\
\text { relevant other parties involved in the MPSO project. }\end{array}$ \\
\hline Environmental Assessment & $\begin{array}{l}\text { PWA as the project owner has consulted with the Ministry of Municipality and } \\
\text { Environment (MME) early in the project planning process to determine whether } \\
\text { the proposed project would require an environmental assessment. A credible } \\
\text { environmental consulting company, following the MME requirements, has } \\
\text { undertaken an Environmental Impact Assessment (EIA) for the project in 2014. }\end{array}$ \\
\hline Baseline Studies & $\begin{array}{l}\text { Environmental data such as water quality, air quality, soil quality, terrestrial } \\
\text { ecosystems, and groundwater quality is collected as part of the baseline studies } \\
\text { associated with the EIA undertaken for the project. Environmental monitoring } \\
\text { program is currently in place to allow for comparison of baseline environmental } \\
\text { data with monitoring data that is being collected through the project life cycle to } \\
\text { identify long-term trends and fluctuations. }\end{array}$ \\
\hline
\end{tabular}




\begin{tabular}{|c|c|}
\hline Environmental Design & $\begin{array}{l}\text { Environmental design criteria have been established and integrated into the project } \\
\text { design. The following have been considered for establishing the design criteria: } \\
\text { - } \quad \text { Consideration of climate change impacts. } \\
\text { - Inclusion of future projections. } \\
\text { - } \quad \text { Coastal management and protection. } \\
\text { Discharging storm water back into the water cycle in a controlled } \\
\text { manner. } \\
\text { - Minimizing impacts on marine water quality and ecosystem. } \\
\text { Achieving required dilution and mixing levels under all current scenarios } \\
\text { for full range of operating conditions and flows. } \\
\text { Minimizing changes in ambient concentrations and impacts on sensitive } \\
\text { habitats such as corals and seagrass. }\end{array}$ \\
\hline $\begin{array}{l}\text { Environmental Management } \\
\text { System }\end{array}$ & $\begin{array}{l}\text { Both the PMC and the Contractor has established an environmental management } \\
\text { system (EMS) for the project in accordance with international best practice, such as } \\
\text { ISO 14001:2015. }\end{array}$ \\
\hline Risk Management & $\begin{array}{l}\text { Project risks are identified, analyzed, and evaluated to ensure that the risks are } \\
\text { effectively managed through the application of a robust risk management process. } \\
\text { Project risk workshops are undertaken at planned intervals with the involvement of } \\
\text { various project stakeholders, an overarching Project Risk Register is maintained to } \\
\text { capture the risks, and the mitigation measures identified. Risk management is part } \\
\text { of the responsibilities of management and an integral part of all project processes } \\
\text { and disciplines. In addition, a separate Environmental Risk Assessment Register is } \\
\text { being maintained throughout the project lifecycle to identify, monitor, and manage } \\
\text { the environmental impacts associated with the project activities. }\end{array}$ \\
\hline $\begin{array}{l}\text { Environmental Management } \\
\text { Plans }\end{array}$ & $\begin{array}{l}\text { Construction Environmental Management Plan and associated environmental } \\
\text { aspect-specific management plans are developed for the MPSO project. These plans } \\
\text { are implemented and updated throughout the project life cycle to ensure continual } \\
\text { improvement. }\end{array}$ \\
\hline Compliance Obligations & $\begin{array}{l}\text { Compliance obligations applicable for the project's environmental aspects have } \\
\text { been identified and the project's compliance is being evaluated through the review } \\
\text { and update of the Environmental Compliance Matrix established for the project. } \\
\text { Moreover, a project Permit Register is established and maintained to track all the } \\
\text { applicable permits for the project, including but not limited to environmental related } \\
\text { permits such as project environmental permit, dewatering permit, dredging and } \\
\text { offshore works permit, chemical storage permit, water treatment plant permit. }\end{array}$ \\
\hline Training and Awareness & $\begin{array}{l}\text { Toolbox talks, topic-specific trainings, and environmental awareness sessions are } \\
\text { being provided at the MPSO project site to raise the awareness of the project staff } \\
\text { on environmental matters. }\end{array}$ \\
\hline Communication & $\begin{array}{l}\text { Weekly and monthly progress meetings are held with the attendance of the PMC, } \\
\text { Contractor, and PWA to discuss the project progress with respect to each project } \\
\text { discipline, including environment. In addition to these meetings, discipline-specific } \\
\text { internal meetings (i.e. environment, HS, marine, tunneling, commercial, etc.) are } \\
\text { held between the PMC and the Contractor to evaluate the status of the project } \\
\text { and to identify any issues of concern.) Progress reporting and presentations are } \\
\text { also done both by the PMC and the Contractor in accordance with the contractual } \\
\text { requirements. }\end{array}$ \\
\hline Performance Evaluation & $\begin{array}{l}\text { Environmental performance of the project is monitored and evaluated through } \\
\text { the use of various tools such as site inspections, internal and external audits, and } \\
\text { monthly management review meetings. Daily, weekly, and monthly site inspections } \\
\text { are completed by both the PMC and the Contractor at all project sites. Internal and } \\
\text { external, PMC, Contractor, and PWA EMS audits are conducted in accordance with } \\
\text { ISO 14001: } 2015 \text { standard, to determine (a) whether the project site is operating in } \\
\text { adherence to compliance obligations (b) whether the EMS and other environmental } \\
\text { plans have been properly implemented and maintained. Monthly, integrated health, } \\
\text { safety, and environmental (HSE) management review meetings are conducted with } \\
\text { the presence of PMC and the Contractor representatives to ensure the continuing } \\
\text { suitability, adequacy and effectiveness of the project EMS. }\end{array}$ \\
\hline Environmental Monitoring & $\begin{array}{l}\text { Environmental monitoring program is in place for monitoring and measurement of } \\
\text { environmental aspects such as air quality, noise, groundwater quality, wastewater } \\
\text { quality, seawater quality, waste generation, and excavated materials. }\end{array}$ \\
\hline
\end{tabular}




\begin{tabular}{|l|l|}
\hline Emergency Planning & $\begin{array}{l}\text { Site-specific environmental emergency plan has been developed and implemented, } \\
\text { tested and updated on a regular basis. The scope of the emergency plan is } \\
\text { comprehensive in nature, and goes beyond the compliance obligations, particularly } \\
\text { with respect to hazard identification, risk } \\
\text { analysis and consequence as well as communications. }\end{array}$ \\
\hline $\begin{array}{l}\text { SWA has set a target for the MPSO project to achieve 'good level' for CEEQUAL, } \\
\text { the evidence-based sustainability assessment, rating and certification scheme } \\
\text { (CEEQUAL, 2015). The Contractor understands the importance of delivering } \\
\text { a sustainability-driven strategy for the MPSO project and conducts regular } \\
\text { CEEQUAL workshops to ensure that the desired level of achievement will be } \\
\text { realized by addressing the requirements of each CEEQUAL category that includes } \\
\text { management, resilience, communities and stakeholders, land use and ecology, } \\
\text { landscape and historic environment, pollution, resources, and transport. }\end{array}$ \\
\hline
\end{tabular}

\subsection{Environmental performance evaluation - site inspections}

Environmental performance of the MPSO project is monitored and evaluated through the use of various tools such as site inspections, internal and external audits, and monthly management review meetings. Daily, weekly, and monthly site inspections are completed by both the PMC and the Contractor at all project sites. Environmental site inspection sheets cover a wide range of topics such as air quality, water quality, noise \& vibration, biodiversity, carbon footprint, emergency planning, record keeping; and permit-specific inspection sheets to evaluate the project's compliance against the conditions set forth in the environmental permits obtained.

Figure 1 below shows the environmental site inspections conducted by the PMC within the past year. As can be seen from the graph, the frequency of the site inspections is increased depending upon certain construction activities. As an example, the dredging works were completed during the month of May 2019, thus the frequency of the site inspections were increased to ensure that the mitigation measures to reduce the potential environmental impacts were implemented adequately and effectively by the Contractor.

It is paramount to adopt a systematic and integrated approach in implementing management systems for a project and MPSO project is a proof of the importance given for environmental management as much as $\mathrm{H} \& \mathrm{~S}$ and quality management for the overall success of the project.

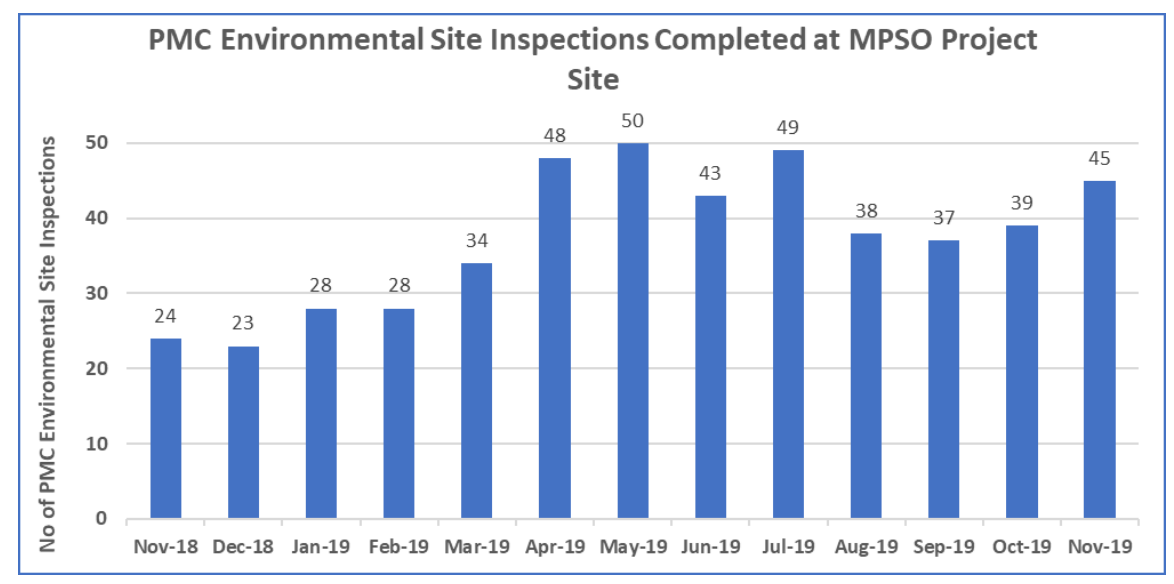

Figure 1: PMC Environmental Site Inspections Completed at MPSO Project 


\subsection{Environmental monitoring - seawater quality monitoring}

Site-wide environmental monitoring is being implemented at specified representative sensitive receptor locations around the project site, for monitoring and measurement of environmental aspects such as air quality, noise, groundwater quality, wastewater quality, seawater quality, waste generation, and excavated materials. As the MPSO project includes the construction of a $10 \mathrm{~km}$ outfall chamber below the seabed, it is of crucial importance to establish the baseline data for the seawater quality to allow for comparison of baseline environmental data with monitoring data that is being collected through the project life cycle to identify long-term trends. With that regard, PWA has clearly defined in the Contract, the requirements for establishing a seawater quality programme that includes monthly seawater sampling and analysis and continual online monitoring of seawater quality through installation of oceanographic buoys. The Contractor prepares and submits monthly analysis reports to present the results of this monitoring exercise. Figure 2 is a demonstration of the results of the seawater quality monitoring at the MPSO project site, from the buoys along with the monthly sampling undertaken.

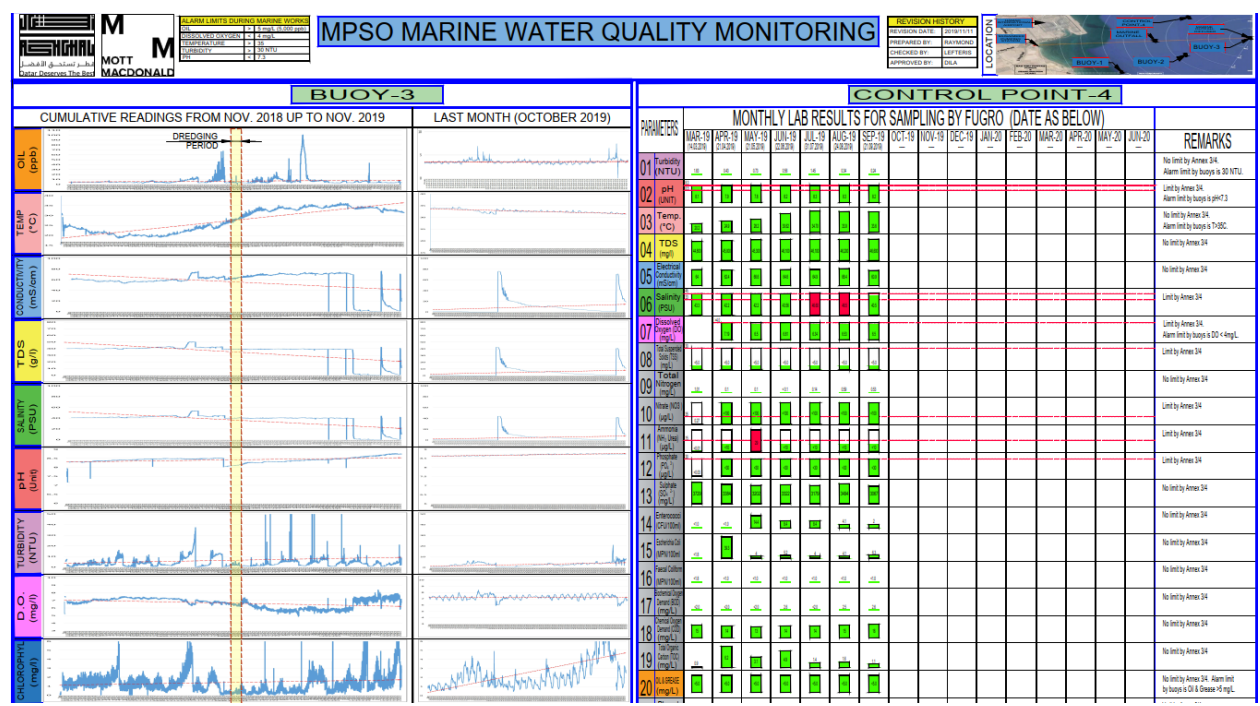

Figure 2: Results from the Seawater Sampling and Online Buoys Monitoring

\section{CONCLUSION}

MPSO project is a proof of PWA's thought-leadership in sustainability and environmental management. PWA's organizational culture that supports the integration of environmental management and sustainability into the project lifecycle has led to the achievement of high/enhanced environmental performance for the MPSO project and also resulted in various other benefits, including but not limited to the following:

- Better use of energy and resources.

- Compliance with legislation.

- Management of environment aspects effectively.

- Protecting the environment by preventing or mitigating adverse environmental impacts.

- Reduced risks. 
- Improved sustainability performance.

- Improved stakeholder confidence and trust.

The recipe for success in achieving high standards for environmental management and sustainability is also dependent on the commitment by all parties involved in the project, including the PMC and the Contractor. PMC and Contractor management also plays a significant role in the successful implementation and maintenance of the established systems by providing adequate financial resources and intangible resources such as support, commitment of time, encouragement of employees that facilitate the adoption and maintenance of the systems. The recipe for success for the MPSO project has been the collaborative approach and the open dialogue between all project stakeholders, including PWA, PMC, and the Contractor, creating solutions together.

\section{REFERENCES}

CEEQUAL Ltd. (2015). CEEQUAL Version 5.2 Assessment Manual for Projects, Qatar International Edition.

Public Works Authority (2017). Professional Services Agreement for Professional Consultancy Services - Post Contract Professional Consultancy Services, Project CP 671/2 Musaimeer Pumping Station and Outfall, Project ID: IA 2016 S 005 G, Contract Number: P2017/22.

Public Works Authority (2017). Contract Documents for Design, Build, Operate and Maintain of Musaimeer Pumping Station and Outfall, Project ID: IA 14/15 C 015 G, Contract Number: C2017/109.

Qatar Construction Specifications (QCS) (2014). Revision IV.

The British Standards Institution (2015). BS EN ISO 14001:2015 Environmental management systems - Requirements with guidance for use, BSI Standards Publication, London. 